\title{
Investigating Future Educators Training to Teach English in Ecuador: An Examination of one University's Program
}

\author{
By Mayra C. Daniel* \\ Ximena Burgin ${ }^{\dagger}$
}

\begin{abstract}
Education in Ecuador is undergoing a process of change led and supported by the country's government leaders. In this study, researchers use a wide-angle lens informed by governmental mandates to investigate English language teaching. They examine how English language teachers are trained for the K-12 Ecuadorian context within one university's region. The 40 participants, students completing a school-based internship during the last year of their training to become teachers, represent a sample of Ecuador's cultural and linguistic diversity. This work is informed by findings from a previous study, consisting of observations and interviews of practicing teachers (Burgin \& Daniel, 2017). Using mixed methods, this research includes surveys and focus groups conducted before and after delivery of instructional workshops centered on topics related to English language instruction and teacher training. Findings indicate mixed-results from pre to post for teachers' cultural beliefs; however, positive change was found regarding participants' attitudes toward multicultural students. Data revealed that teachers require more support to deliver instruction that is appropriate for monolingual and multilingual student populations.
\end{abstract}

Keywords: English language teaching, multilingualism, teacher training.

\section{Introduction}

The investigation discussed in this article was conducted by two Latin American professors who reside in the United States (U.S.). They are native speakers of Spanish whose schooling in Latin America ranges from seven to 16 years in length in the countries of Cuba and Ecuador. They have histories of working with teachers in the northern and southern hemispheres of the Americas, and with immigrant populations of students at levels K-12 in the U.S. This work examines English language teaching (ELT) in one university' teacher instruction program. Keeping in mind Ecuador's top-down educational mandates of the past decade as a backdrop to curricular requirements (Van Damme, Aguerrondo, Burgos, \& Campos, 2013), this work examines how students finishing their teacher training program perceive they have been prepared to teach English, and to consider the country's cultural and linguistic diversity in lesson planning.

In this study, pre-workshop and post-workshop surveys were administered

${ }^{*}$ Professor, Northern Illinois University, USA.

${ }^{\dagger}$ Associate Director Research and Innovation Partnerships, Northern Illinois University, USA. 
to teacher candidates (students completing a school-based internship during the last year of their training to become teachers), prior to and after participation in nine instructional workshops focused on ELT methods. The surveys explored these interns' (future teachers') perceptions of the quality of their university's training and its focus on ELT. In addition, the surveys provided data to evaluate changes in the participants' espoused philosophy of ELT before and after attending the workshops.

After the workshops, focus groups were held and data was used to document the knowledge and pedagogy of ELT that participants shared they had developed in the workshops. These provided an opportunity for the interns to voice additional questions, and to explore their future needs in professional development after graduation, unique to the particular needs of students and teachers in Ecuador.

\section{Background to the Ecuadorian Context}

Ecuadorian educators' work requires a consideration of the sociocultural context of the schools, the communities, and an awareness of the support available to all stakeholders to validate learners' rights (Van Damme, Aguerrondo, Burgos, \& Campos, 2013; Freire, 2002). These researchers believe that when students' basic needs are unmet, educational achievement is likely to be compromised. An issue that is of grave concern in Ecuador that influences this study and the participants, is the availability of potable water and bathrooms in the country's rural areas. Estimates for 2015 projected $86.9 \%$ of Ecuador's population would have access to potable water $(93.4 \%$ in urban areas, and $75.5 \%$ in rural areas), and that $84.7 \%$ of the population (87\% in urban areas and $80.7 \%$ in rural areas) would have access to sanitation facilities (Instituto Nacional de Estadísticas y Censos, 2015).

Ecuador's cultural and linguistic diversity is visible in the many living languages spoken across this nation. The Instituto Nacional de Estadísticas y Censos (2015) documented 93\% of Ecuador's population speaks Castilian and 4.1\% speak Quechua. The newspaper El Tiempo (2015) reports 14 indigenous languages (including Quechua). Ethnologue (2016), a trusted source of information for world languages, identifies 25 indigenous languages for the country, placing 24 in the category of living languages, with 21 of the 25 categorized as indigenous. The INEC (2015) provided 2010 census information reflecting the cultural diversity of the country's population was composed of mestizos (mixed Amerindian and white) 71.9\%, Montubio 7.4\%, Amerindian $7 \%$, white $6.1 \%$, Afroecuadorian $4.3 \%$, mulato $1.9 \%$, black $1 \%$, and other $0.4 \%$.

One challenge to reaching educational equity in Ecuador is that for learners of indigenous descent, achieving mastery of English means learning to communicate in a third language. Part of the country's ongoing curricular redesign reflects a focus on increasing the economic solvency of its population. This model of teacher education is based on teacher competency, and on the addition of English language instruction across the country's schools. Student evaluations 
such as the Ser Estudiante exam (Resultados Pruebas Censales, 2008) are used to identify areas in the curriculum that require increased time allocations and/or different instructional foci and revised delivery methods. Given the aforementioned research-based information, it is logical that all Ecuadorian educators be prepared to understand and espouse philosophies that demonstrate appreciation of the country's diversity within the ELT curriculum. Clearly, addressing Ecuador's cultural and linguistic diversity and adding English to the curriculum, places increased responsibilities on teacher trainers. These added demands include increasing the levels of inter-cultural understandings of future teachers, and thus ensuring that schooling is equitably offered to all of the country's citizens (Constitution of the Republic of Ecuador, 2011).

This inquiry was precipitated by the researchers' awareness of the educational changes in Ecuador that have resulted from top down mandates set forth by the country's leaders. Changes have aimed to increase teacher quality, raise the literacy rate, and add ELT to the curriculum at levels K-12 (Gallegos, 2008). There has been a substantial shift in the way teacher competency is now evaluated in Ecuador (Cevallos-Estarellas, \& Bromwell, 2015). Ecuador's leaders seek to better prepare its children for the global marketplace by monitoring and linking student progress to what their teachers do in the classroom. The movement to design curricula that appropriately meets educational needs across all segments of Ecuador's society, includes the added requirement of English instruction in the curriculum at K-12 levels (Malik, Esaki-Smith, Lee, \& Nagan, 2015).

Some factors to consider are the demonstrated positive trends in Ecuadorian education. For the year 2010, the Instituto Nacional de Estadísticas y del Censos (2015), estimated that $93.2 \%$ of Ecuadorians were literate, and the Ecuadorian Demographic Profile (2016) predicted this figure would increase by approximately $1.5 \%$ each year. Therefore, given the documented levels of Spanish literacy in Ecuador, this inquiry does not look to examine literacy instruction in the country's dominant language. This research documents how teachers perceive they are prepared to teach English. We present future educators voices prior to and after participating in instructional workshops focused on how teachers might improve design and delivery of effective ELT when planning lessons for Ecuador's multicultural multilingual context.

This research is based on a sociocultural framework of teaching and learning, and on theoretical understandings that SLA processes are enhanced by balanced literacy instruction that supports students' academic growth within their zone of proximal development (Vygotsky, 1986). In schools, this requires both teacher and student led instruction, and at the same time situates students and teachers as co-learners who open doors to view each other's unique cultural contexts (Daniel, 2016). Wertsch (1990) emphasized that the teacher and the students are co-learners in classrooms where students support each other's learning, and take turns taking on the role of being the expert.

This work explores ways to guide Ecuadorian teachers in informed reflective practice to help them identify questions they have not previously considered. These processes will allow them to expand their knowledge base and experiment implementing new strategies for learning in their classrooms. This research 
investigates the pedagogy that participants were being taught in their training and possibilities for improved practice in ELT.

\section{Procedures for Data Analyses of Focus Groups Conducted Before and After Instructional Workshops}

Focus group conversations were examined qualitatively and quantitatively to identify significant recurring themes in the data (Corbin \& Strauss, 2008). Prior to conducting this work, the researchers hypothesized which themes might emerge in the focus groups. However, some of the themes that emerged were surprising because they revealed the interns held negative opinions about their training. Symbolic convergence theory (SCT) (Daniel, 2010) was used to identify and analyze the themes that resulted in greater emotional commitment and convergence in the participants, suggesting agreement, creation of new ideas, and interpretations.

SCT is a theory that has been used in marketing and advertising to identify projects that will be successful such as the riverboat casinos in the state of Iowa in the United States (US). SCT has also served well to examine the birth and development of new ideas in education and educators' voiced concerns about issues of social justice (Daniel, 2010). SCT delves into individuals' psyche because it is a vehicle for identifying and acknowledging everyone's realities.

SCT posits that human beings create their fantasies and realities through the messages that are communicated to them in their lives, and through the intra- and inter- personal interactions that subsequently arise. Human beings are thus understood to be actors who justify their philosophies as their realities evolve. In this study, the participants developed ideas that were not judged in data analyses to be accurate or false. The accuracy of the ideas per the researchers' realities was not the important issue. Rather, participants' personal involvement revealed challenges in ELT in Ecuador and what educators in this country consider is needed to improve instruction.

\section{Methodology of Research}

\section{Needs Analysis}

Before this intervention began, a needs assessment was conducted consisting of two protocols. First, in a previous study, the authors conducted observations of nine secondary level English teachers (Burgin \& Daniel, 2017; Daniel \& Burgin, 2016), using the Classroom Observation Checklist (2010). These served to analyze practicing Ecuadorian teachers' delivery of content, lesson organization, classroom interactions, verbal and non-verbal communication in the classroom, and integration of media during instruction in English classes (Burgin \& Daniel, 2017; Daniel \& Burgin, 2016). Along with the observations, practicing educators answered open-ended questions related to how future teachers are trained in Ecuador (Daniel \& Burgin, 2016). Responses to both the survey and the open- 
ended questions asked in this prior work, provided insights into how teachers are trained to consider the cultural and linguistic diversity of students in Ecuador.

\section{Rationale for Workshops}

In effective ELT models, educators recognize students' linguistic and cultural funds of knowledge (Goodman \& Allen, 2017; González, Moll, \& Amanti, 2005; Ruiz, 1984). They are aware that sociocultural underpinnings contribute to learners' evolving understandings of the cultures of the English-speaking world. Effective English teachers possess two important professional and personal qualities. They teach the target language of study and function as cultural brokers (Hall, 2016). Models of balanced literacy align to second language acquisition (SLA) philosophies that acknowledge the power of the home's contribution to literacy and cognition. Competent teachers demonstrate in their curriculum that they value the students' in and out-of-school networks across the home, the school community, and the neighborhood.

Answers to the following questions posed to practicing teachers in a previous study (Burgin \& Daniel, 2017), were used to develop this study's overarching question and three sub-questions:

How adequately do students in their teacher training program perceive they are prepared them to lead their students to academic success and mastery of English?

a. What pedagogies are taught to students training to become English teachers?

b. What components of intercultural education are part of the English language teacher training curriculum?

c. What are students in Ecuador taught in their training to become teachers that focuses on ways to address their society's cultural and linguistic diversity in ELT?

Specifically, the questions that guided this mixed methods study focused on identification and exploration of teacher interns' perceptions of the ways the curriculum in their teacher training program prepared them to teach English.

Q. 1: How do students perceive they have been prepared to deliver effective ELT?

Q. 2: How do students being trained to teach English consider Ecuador's cultural and linguistic diversity in their lesson planning?

\section{Participants and Site of Workshops}

The workshops were delivered at a state university in Ecuador that prepares teachers to teach English in the K-12 school system. A total of forty interns in the last semester of their studies were invited to participate. Study participants 
$(\mathrm{n}=40)$ were in their clinical placements completing a year-long internship at K-12 schools in the region of the university. During the internship period, interns experience teaching lessons to students only after they prepare and submit lessons to their supervisor for approval. Participants, all between 22-25 years of age, were evenly divided between males and females. They were also complying with the graduation requirement of writing a thesis, at the same time that they were in their clinical internships.

Pre/post surveys were administered to the participants before and after the instructional workshops, to determine if there was a change in the participants' knowledge and skills. At the completion of the workshops, a group forum was conducted to ask the participants questions about what they had learned, to answer remaining pedagogical questions on the part of the participants and researchers, and to explore topics that might be addressed in future workshops.

\section{Appropriate Selection of Workshop Topics}

Workshops topics were selected if they met the criteria that they would serve as the vehicle for the interns to identify and reflect on the challenges they might encounter as teachers of English. We wanted to help interns reflect on the challenges that we had identified they might face in their careers as English teachers.

Themes selected for the workshops also evolved from the researchers' belief that all languages need to be viewed as a resource for teaching and learning (Ruiz, 1984). Ruiz's philosophy raises educators' awareness of the key roles that culture and language play in education. A culturally relevant ELT curriculum assigns equal status to all the cultures and languages represented by the classroom demographic and do not privilege some learners over others (Daniel, 2016; Faust, 2016; Kincheloe, 2008; Hawkins \& Norton, 2009). We believe that SLA is a complex process (Bialystok, 2011) that can be examined by looking at what learners do as they progress through stages of language development, and as they are given opportunities to compare and contrast their cultures and languages with those of English speakers. In the classroom, SLA requires a balance of implicit and explicit pedagogy. Language educators know that in the real world and in classroom environments, learners acquire additional languages as they use all their linguistic expertise to make meaning as they translanguage for understand (García \& Wei, 2014; Canagarajah, 2013).

\section{Planning the Workshops}

Prior to conducting the instructional workshops, the planning consisted of two phases: a needs assessment of the participants and focus groups. Only informal focus groups were conducted after the instructional workshops.

\section{Pre-Workshop Surveys}

Before the instructional workshops, a needs assessment of the participants' 
knowledge about second language teaching strategies, and interventions for cultural and linguistically diverse school environments was performed, using a survey instrument and conducting focus groups. Information gathered was helpful in adjusting the materials to be delivered during the instructional workshops. Pre-workshop surveys served to investigate and document participants' philosophies underlying the ELT instructional methods taught to them in their training.

Data were examined to establish how interns perceived their teacher training was preparing them to address diversity and teach English. Survey questions addressed components of intercultural education present in the secondary level English curriculum (See Table 1: Section 1 Teacher's Cultural Beliefs and Table 2: Section 2 Attitude towards Multilingual Students in the findings). Section I of the survey contains 21 questions and Section II includes 13 questions: both sections used a dichotomous scale ( $\mathrm{Yes}=1$ and No $=2$ ). Pre- and postworkshop surveys were matched through a code assigned to participants.

\section{Pre-Workshop Focus Groups}

Four focus groups were conducted with interns before they participated in instructional workshops. Data were used to identify topics to address in the workshops, and to decide how to best scaffold the topics selected for the workshops. A review of the professional literature centered on the educational changes of recent decades in Ecuador, was used to interpret the focus group data.

In the pre-workshop focus groups, the interns were asked:

1. What strategies for teaching English were taught in your teacher training program?

a. How were you taught to teach these ELT strategies to monolingual students?

b. How were you taught to teach these ELT strategies to bilingual and trilingual students?

c. How were you taught to use instructional strategies in ELT to evaluate student learning?

\section{Focus Groups after Workshops}

Informal focus groups, conducted after the instructional workshops, continued the inquiry of future teachers' perceptions of (1) how training programs prepare future teachers to teach English to Ecuador's diverse student populations and, (2) to identify what future professional development for practicing teachers might be most beneficial for the Ecuadorian context.

The post workshop focus groups were guided by the following questions:

1. What have you learned about teaching English to monolingual students 
and to learners who may speak an indigenous language (as a first language), Spanish as a second language, and are in the process of studying English (a third language)?

a. What instructional support do monolingual students need?

b. What instructional support do multilingual students need?

2. What is your understanding of the multiculturalism present in Ecuador's student population? Share your definition of multiculturalism.

3. What other questions do you have for us [the researchers]?

After the instructional workshops were delivered, data from post-workshop surveys and post-workshop focus groups were used to document interns' questions related to ELT and future professional development needs.

\section{Analysis of Results}

Nine workshops were presented over three days with a total of 15 hours-- 5 hours per day. The number of workshop participants was 40 for many of the workshops. However, the quantitative data indicates that complete data (surveys and participation in focus groups and workshops) was collected on only 19 participants. Due to this small number of responses, the researchers could not perform the desired data analyses (e.g., paired $t$-test). Thus, descriptive statistics are presented. A data analysis at the individual level was performed to determine the number of participants who changed their answers either positively, (from no in pre-test to yes in post-test), or negatively, (from yes in pre-test to no in post-test).

The purpose of surveying participants before and after the workshops, was to determine these future teachers' perceptions of diversity for their context, their knowledge of how to use and teach students teaching strategies in ELT, and to establish their ability to plan content and language objectives for lessons (See Table 1 Section 1 Teacher's Cultural Beliefs and Table 2 Section 2 Attitude Survey).

Results of the Teachers' Cultural Beliefs survey seem to indicate that participants changed their perceptions positively about the influences on instruction of teachers' cultural beliefs. Regarding the Attitudes toward Multilingual Students survey, participant responses indicated a positive change from pre to post-test. Positive change reflects the participants' awareness of different cultural norms and multilingual students' academic needs. 


\section{Section 1: Teachers' Cultural Beliefs Survey}

Table 1. Section I Teachers' Cultural Beliefs

\begin{tabular}{|c|c|c|c|c|}
\hline \multirow[b]{2}{*}{ Questions } & \multicolumn{2}{|c|}{ Pre test* } & \multicolumn{2}{|c|}{ Post test* } \\
\hline & Yes & No & Yes & $\mathrm{No}$ \\
\hline $\begin{array}{l}\text { 1. Teachers should incorporate elements of student culture in } \\
\text { lessons. }\end{array}$ & 19 & 0 & 18 & 1 \\
\hline $\begin{array}{l}\text { 2. Schools/teachers should encourage minority students to } \\
\text { become integrated into the existing school culture by giving } \\
\text { up their own cultural values. }\end{array}$ & 2 & 17 & 6 & 13 \\
\hline $\begin{array}{l}\text { 3. Schools/teachers should adapt their school cultures to the needs } \\
\text { of minority students. }\end{array}$ & 16 & 3 & 18 & 1 \\
\hline $\begin{array}{l}\text { 4. Should teachers focus on content dictated by the school } \\
\text { curriculum without thinking about student cultural } \\
\text { background? }\end{array}$ & 1 & 18 & 4 & 15 \\
\hline $\begin{array}{l}\text { 5. Teachers have little available time to plan and provide } \\
\text { culturally responsive curriculum in content area classrooms. }\end{array}$ & 17 & 2 & 16 & 3 \\
\hline $\begin{array}{l}\text { 6. Minority students' home cultures or environments influence } \\
\text { learning. }\end{array}$ & 14 & 4 & 17 & 2 \\
\hline $\begin{array}{l}\text { 7. Using elements of the student's culture in curriculum and } \\
\text { lesson planning is not necessary because all students need to } \\
\text { become integrated into the existing school culture. }\end{array}$ & 9 & 10 & 11 & 8 \\
\hline $\begin{array}{l}\text { 8. Providing first language services for minority language } \\
\text { students is not necessary because they need to learn the } \\
\text { dominant language. }\end{array}$ & 17 & 2 & 18 & 1 \\
\hline $\begin{array}{l}\text { 9. Maintenance of the first language is not important for academic } \\
\text { success of language minority students. }\end{array}$ & 16 & 3 & 18 & 1 \\
\hline $\begin{array}{l}\text { 10. Maintenance of the first language is not important for life } \\
\text { success of minority language students. }\end{array}$ & 16 & 3 & 17 & 2 \\
\hline $\begin{array}{l}\text { 11. Minority language students should speak the school language } \\
\text { at home. }\end{array}$ & 12 & 7 & 14 & 5 \\
\hline $\begin{array}{l}\text { 12. Minority language students should be allowed to speak the } \\
\text { home language at school. }\end{array}$ & 18 & 1 & 17 & 2 \\
\hline $\begin{array}{l}\text { 13. Special services should be provided for minority language } \\
\text { students. }\end{array}$ & 12 & 7 & 15 & 4 \\
\hline $\begin{array}{l}\text { 14. Classes in the language used at school should be provided for } \\
\text { them to master speaking the new language. }\end{array}$ & 18 & 1 & 17 & 2 \\
\hline $\begin{array}{l}\text { 15. Multilingual assistance such as individual help in first } \\
\text { language, contact with parents, translation. }\end{array}$ & 14 & 5 & 13 & 6 \\
\hline $\begin{array}{l}\text { 16. Multilingual courses in subject areas (incorporating first } \\
\text { language) should be provided. }\end{array}$ & 18 & 1 & 15 & 4 \\
\hline $\begin{array}{l}\text { 17. Courses in development of academic language in their first } \\
\text { language (reading, writing etc.) should be provided. }\end{array}$ & 19 & 0 & 15 & 4 \\
\hline $\begin{array}{l}\text { 18. Bilingual school personnel for communication with students } \\
\text { and parents/families should be provided. }\end{array}$ & 19 & 0 & 16 & 3 \\
\hline $\begin{array}{l}\text { 19. Multilingual students have different learning needs because of } \\
\text { their background. }\end{array}$ & 12 & 7 & 14 & 5 \\
\hline $\begin{array}{l}\text { 20. Multicultural students have different learning needs because } \\
\text { of their background. }\end{array}$ & 11 & 7 & 16 & 3 \\
\hline $\begin{array}{l}\text { 21. When learning to read for the first time, multilingual students } \\
\text { should learn to read in the language used at school. }\end{array}$ & 16 & 3 & 15 & 4 \\
\hline
\end{tabular}
$* \mathrm{n}=19$ 
Table 1 shows the comparison between the pre- and post-test responses for questions 1-21 of the Teachers' Cultural Beliefs. Out of the 21 questions, participants changed responses in nine questions from yes in pre-test to no in post-test in the post-test ranging from 1 to 4 participants. Participants changed their answers to questions that relate to supporting multilingual students. For example, participants changed their answer from yes to no concerning bilingual support to communicate with parents, that multilingual courses should be provided, and that teachers provide multiculturally responsive curriculum. These may indicate that teachers need support to implement pedagogy that would benefit multilingual students. Regarding the other 12 questions, participants changed from $n o$ in the pre-test to yes in the post-test with a range of 1 to 5 participants. These findings seem to indicate that teacher realized the supports that multilingual student need. These findings suggest that in their reflections, participants recognized the multilingual students need instructional support that should be provided by teachers; however, participants also realized the time commitment and resources needed to meet students' needs.

\section{Section II: Attitudes toward Multilingual Students Survey}

Table 2. Section II Attitudes toward Multilingual Students

\begin{tabular}{|l|c|c|c|c|}
\hline & \multicolumn{2}{|c|}{$\begin{array}{c}\text { Pre test } \\
\text { (n=19) }\end{array}$} & $\begin{array}{c}\text { Post test } \\
\text { (n=19) }\end{array}$ \\
\hline Questions & Yes & No & Yes & No \\
\hline 1. I feel confident modifying lessons for culturally diverse learners. & 8 & 11 & 14 & 5 \\
\hline 2. I know how to write a content objective. & 14 & 5 & 16 & 2 \\
\hline 3. I know how to write a language objective. & 8 & 11 & 14 & 5 \\
\hline $\begin{array}{l}\text { 4. I know how to identify cultural aspects of a students' identity } \\
\text { that impact his/her learning. }\end{array}$ & 5 & 14 & 12 & 7 \\
\hline $\begin{array}{l}\text { 5. I feel confident identifying students' needs based on their first } \\
\text { language. }\end{array}$ & 7 & 12 & 13 & 5 \\
\hline $\begin{array}{l}\text { 6. I feel confident designing curriculum for students who speak } \\
\text { Spanish at school and indigenous or other language at home. }\end{array}$ & 1 & 18 & 13 & 6 \\
\hline $\begin{array}{l}\text { 7. I am sensitive to the socio-affective needs of culturally diverse } \\
\text { students. }\end{array}$ & 17 & 2 & 19 & 0 \\
\hline $\begin{array}{l}\text { 8. I know how to determine whether my students have unique } \\
\text { needs because they are from a minority culture. }\end{array}$ & 7 & 12 & 16 & 3 \\
\hline $\begin{array}{l}\text { 9. I know how to determine whether my students have unique } \\
\text { needs because they speak a minority language. }\end{array}$ & 5 & 14 & 13 & 5 \\
\hline $\begin{array}{l}\text { 10. I use a variety of methodology to help multilingual learners } \\
\text { achieve academic success. }\end{array}$ & 8 & 11 & 15 & 3 \\
\hline $\begin{array}{l}\text { 11. I know how to incorporate graphic organizers in content area } \\
\text { instruction. }\end{array}$ & 8 & 11 & 14 & 4 \\
\hline $\begin{array}{l}\text { 12. In my work I feel confident using the same language } \\
\text { objectives for monolingual Spanish speakers that I use for } \\
\text { linguistically diverse learners. }\end{array}$ & 3 & 16 & 14 & 4 \\
\hline $\begin{array}{l}\text { 13. I feel confident engaging students in literacy activities using } \\
\text { graphic organizers. }\end{array}$ & 13 & 6 & 14 & 4 \\
\hline
\end{tabular}


Table 2, offers a dichotomous comparison between pre and posttest answers to questions 1-13 for the Attitudes toward Multilingual Students Survey. For these questions from one to 12, participants changed their answers from no in the pre-test, to yes in the post-test. One to two participants changed from no in the pre-test, to yes in the post-test about writing content objectives, being sensitive to the socio-affective needs of culturally diverse students and feeling confident engaging students in literacy activities using graphic organizers. Regarding writing language objectives, 11 participants in the post test changed their answer to that yes, they felt confident selecting language objectives for both monolingual and linguistically diverse learners. The highest number of participants changing their answer from no in the pre-test, to yes in the post-test was twelve regarding designing curriculum for monolingual or multilingual students. Results demonstrate the participants changed their attitudes toward multilingual students as a result of participating in the workshops.

\section{Limitations of this Study}

Determining participants' change in knowledge/skills gained in participation in the workshops through the calculation of the effect of the workshop (power) was not possible due to the small number who participated in all the workshops (19). Another issue that the researchers learned was that the dichotomous scale used in the survey did not allow for an accurate examination of participants' change in knowledge. Changing the dichotomous scale of the survey to a fivepoint Likert scale would allow respondents to indicate the level of multilingual content and attitude before and after the workshops. The second possibility to better determine outcomes, would be to use a retrospective pre and post survey design. In this case, the pre-survey is administered simultaneously with the post survey by asking the participants to recall their knowledge prior to the workshops (Allen \& Nimon, 2007).

\section{Discussion of Results}

Focus groups data indicated that practicing teachers have the dispositions needed to help Ecuador's culturally and diverse students and that they have the cultural awareness to be able to effectively consider learners' academic and affective needs. In contrast, the data indicated that teacher candidates do not feel prepared to act upon the diversity of student populations once they begin their work as teachers in charge of their classrooms. Teacher candidates' comments evidenced their need of more professional development regarding formative and summative assessments, and the types of expertise and tools they might need to support students' academic progress.

Data from the surveys suggests a positive change in the attitudes and perceptions of the participants after the workshop, regarding cultural beliefs and attitudes toward multilingual students. The positive change was reflected in changed responses from pre to post-test and what these suggest in participants' 
perceptions. In addition, it is of great interest to the researchers that findings reveal that five participants changed from no in the pre-test to yes the post-test for Q20 (Multicultural students have different learning needs because of their background). This change strongly supports a change in participants' views of how the academic needs of multicultural students are impacted by their backgrounds and funds of knowledge. Concerning the Attitudes toward Multilingual Student's survey, after the workshop, twelve students stated that they felt confident to design curriculum for monolingual and multilingual students, including making modifications needed regarding the initial identification needs assessment of students, and subsequent academic needs.

\section{Interaction of Results}

The discussion that follows is twofold. It presents the data analysis of the survey questionnaire and the focus groups before and after the instructional workshops. Data analyses of surveys administered before and after the instructional workshops

\section{Survey Questionnaire Data Analysis}

\section{Section I: Cultural Beliefs}

Answers to questions on the Teachers' Cultural Beliefs Survey (Table 1) yielded two findings. First, there was little change between the pre- and post test results. Secondly, an examination of responses for Questions 17, 20, and 21 , reflects conflicts in interns' philosophies of instruction, and suggest that practice does not support espoused ELT philosophies. Interns agree that "... multicultural students have different learning needs because of their background (Q. 20), and that schools should offer "courses that foster development of academic language" in students' first language (Q. 17). In contrast, responses to Q. 21 "... multilingual students should learn to read in the language used at school", indicate that instruction in Ecuadorian schools overlooks the indigenous languages spoken by many students, recognizes Spanish as the language of instruction, and identifies English as the target language of study for the reason that it will gain learners greater economic success.

\section{Section II: Attitudes toward Multilingual Students}

Data presented in Attitude towards Multilingual Students (Table 2) supports findings in Table 1. The interns acknowledge their sensitivity to the socio-affective needs of culturally diverse students (Q.7), but are not adjusting instruction. Preworkshop responses of three yeses compared to 16 for Q. 12, reveal the true state of practice. Interns (14 of 19) agree with the statement "In my work I feel confident using the same language objectives for monolingual Spanish speakers that I use for linguistically diverse learners". 


\section{Focus Groups: Data Analysis}

\section{Before the Instructional Workshops}

Salient themes in the pre-workshop focus groups can be divided into the following categories: (a) use of teaching strategies, (b) being an organized teacher, (c) feeling a high degree of uncertainty about how to teach and assess strategically and, (d) that in their training the topic of culture was not addressed.

Teaching strategically. The interns indicated that during their training they were taught visual, auditory, and interactive strategies for instruction. They shared that teachers can only select strategies after they identify and understand students' educational needs. One mentioned that "teaching should be interactive if the teacher is to support understandings of the new material". Another intern indicated that it is important to "assess grasp of new concepts through speaking tasks or essays that support students' learning." Yet a third intern stressed three strategic steps to teaching well are to maintain (1) an organized classroom, (2) to make sure all students are polite and, (3) to select appropriate materials for instruction.

Participants explained that they implement many foreign language strategies for learning after they develop lessons and select the materials they will use. This information reflects that they strive to understand students' academic needs and adjust instruction accordingly. None of the interns provided examples of any one strategy that they used when teaching during the internships. The lack of specific information about use of instructional strategies in teaching could be attributed to (1) the level of teaching experience of interns who had not been managing a classroom of students without the assistance of their supervisor, (2) their perception that the instructors who trained them had not offered sufficient modeling and (3) that they were still working to translate theory into practice.

Issues of Assessment. The majority of the interns emphasized that processes for assessing students in English classes had not been clearly explained to them in their training. They agreed that assessment techniques that were part of their training seemed ineffective evaluation methods. They stressed needing to learn more ways to measure students' achievement. Perhaps the interns' uncertainty about assessment protocols relates to the pressure the interns anticipate when they look ahead to their own evaluations as teachers. In addition, the interns shared that they will be provided the materials they need to teach by the government, and that this will delimit their ability to make adjustments to both instruction and assessment.

Organization of instruction. The interns stressed the importance of the teacher being organized while presenting new vocabulary and grammar. The limits of the information shared revealed that interns' knowledge of ELT methodology does not include the ability to apply current theories of SLA. For example, they stressed that an important instructional strategy is that "while reading materials written in English, the students prepare a list of new vocabulary words." They did not appear to consider that memorizing the meaning of a lengthy 
list of words might overwhelm students. They agreed that students' evaluations need to assess their ability to "find the definition, draw the meaning of the word, and use the new word in a sentence."

In contrast, the interns mentioned that an effective way to instruct is for the teachers to ask students to learn how two words can be used in two different contexts each day's lessons. They stated that "Students look up word definitions in the dictionary and write sentences, or the teacher writes a word on the board, defines it, and asks students to use the word in a sentence".

Culture. Participants agreed that in their teacher training, the topic of multiculturalism was "practically not mentioned", and that they had not had "any experience with multilingual students." They stated "we don't know details about multiculturalism but we know that we have to respect different customs." They explained multiculturalism helps educators "to learn about students' cultures, and to get to know them individually". They shared what they know about being bilingual or trilingual they "learned from educators from the U.S. who have visited Ecuador and told us how people in the U.S. act", and not through "any formal education."

\section{Focus Groups Post-workshops}

Salient themes in the post-workshop focus groups can be divided into the following categories: (a) grasping and meeting the academic needs of culturally and linguistically diverse students, (b) being able to demonstrate their understandings and ability to apply current SLA theories in instruction, (c) recognizing learners' cultural capital, (d) understanding the diversity in Ecuador and, (e) wholehearted agreement of professional development needs after graduation.

Meeting students' academic needs. Findings reveal that after the workshops the interns demonstrated clearer understandings and ability to identify monolingual and multilingual students' academic needs. Comments reflected their previous personal and educational experiences in learning English. Prior to the workshops, none mentioned that cultural and familial influences on learning require differentiated instruction for diverse students.

An intern mentioned that many students speak Quechua at home, while another teacher referred to his classmates from other countries speaking different languages. Another intern mentioned that "for speakers of an indigenous language, learning a new language is not difficult." Although not all of the interns agreed with this statement, many nodded their heads and voiced comments demonstrating agreement with the position that if given enough instructional time, multilingual students can learn another language easily. An intern's reflection of his experience studying English elicited agreement across participants. He focused on the different accents that he had heard. "I learned that English accents from Latino and Chinese backgrounds classmates are different. There were words that I found hard to understand because of how they were pronounced. I know that the accent depends of one's country of origin."

Another intern provided an example of her time working with an indigenous 
community: "for children who master Quechua at home and do not speak Spanish well [no mastery of Spanish], learning English is not easy...this happens even when teachers try to reinforce the new knowledge at the beginning of the instruction time." Another intern seemed to agree with her classmate, but her words showed a lack of clarity about the topic of the ongoing conversation. She shared that "Indigenous students are not able to express themselves either in Spanish or English, although they adapt themselves to the environment." The majority of the interns believed that having students who have not mastered Spanish poses a barrier to teaching English. They concluded that because "the students cannot receive help in their own language; help is given either in Spanish or English. It was apparent that the teachers use Spanish to clarify the English grammar and vocabulary they are teaching.

SLA theories and instructional planning. It is noteworthy that none of the interns identified SLA theories by name nor compared and contrasted different approaches to ELT other than to mention skill building strategies. Regarding best practice for monolingual and multilingual students, a candidate indicated and many others agreed that, "rural areas need knowledgeable teachers; including those who understand learning strategies and pedagogy." It was suggested that "the English teacher should know the dominant language of the area where he/she teaches because this makes the teaching better." In addition, the interns mentioned that "building trust, acting professionally, and being helpful to students would help students learn". Another intern indicated that "students who know two languages tend to first relate new knowledge to the already mastered language, then the student learns the words in English, and then the student can retain the new knowledge."

Students' cultural capital. An intern pointed out that "other languages should be valued....the classroom teacher should be knowledgeable about the indigenous language, the topic of instruction, and the students' culture." Another teacher candidate paralleled the answer by indicating that "students talking about topics that are familiar leads to meeting learning objectives." An obstacle mentioned to learning English among indigenous groups was the fact that in recent years students have had instruction in English for only two to three hours per week; "students from different ethnic backgrounds such as indigenous, mestizos, and afroecuatoriano do not answer in English due to the short time exposed to the English language."

Participants acknowledged the need to support multilingual students' needs even when learning goals are not met. The interns indicated that Spanish monolingual students may not need as much instructional support as students whose home language is Quechua. They recognized that classroom teachers play a very important role in supporting students, meeting their academic needs, and helping them lean new material.

Diversity in Ecuador. The interns explained diversity based on their understanding of their context. They acknowledged the existence of many ethnic groups in Ecuador, and the differences across these cultures. One intern mentioned that "we are used to living among different cultures such as the mestizos, afroecuatorianos, and indigenous groups." Another teacher candidate used an 
example indicating that the "afroecuatorianos de la sierra (from the mountainous regions) live differently from the afroecuatorianos de la costa (from the coast)." The interns recognized that "Ecuadorians share a multicultural background although being unique at the same time...which generates different perspectives." Another teacher candidate indicated that "students need to share their own culture and their own ways of living with others, and by exchanging experiences they can learn from each other."

Several interns explained what they consider an issue regarding curriculum for ethnic groups living in rural areas. Comments do not reflect knowledge of governmental mandates to require English in the curriculum across all levels. The interns indicated that "the Department of Education in Ecuador does not require teaching English at the elementary level in these areas; thus, teachers need to prepare their own materials; and teaching English at the elementary level becomes a partnership between the classroom teacher and the parents. Classroom teachers will teach English as long as parents will provide the requested materials." Another intern pointed out that interdisciplinary support for teaching English would be beneficial to engage students and meet objectives for ELT." Yet another intern followed this comment by expressing the need for more support from school administrators.

Professional development and questions for the researchers. Voiced comments suggest that participation in the instructional workshops led the interns to identify what else they want to learn. Their reflections led them to pose many questions about SLA. They began to identify what they do not know. Recurrent themes in their questions suggest uncertainty as they look ahead to beginning their teaching careers, and acknowledge the shortcomings of their training. Their inquiries related to their training to teach English and their philosophical stances.

They asked questions about (1) error correction, (2) what the relationship should be between students and teachers, (3) if teachers should be the ultimate authority or collaborate with students as they teach, (4) what the ideal order for teaching the language domains should be and what the best way is to connect reading, and writing with speaking, (5) in what ways teachers can help students who are struggling to learn and, (6) how to better teach special need students. The interns asked two key questions that reflect their professional development needs; "What are the problems of children who are learning two languages" and "How are these learners affected academically?"

\section{Conclusions}

Data analyses strongly suggest that future research needs to engage Ecuadorian educators in reflective practice. The goal will be for future teachers to do more than acknowledge that there is considerable cultural and linguistic diversity in Ecuador. The interns recognized that different ethnic groups in Ecuador speak different languages, have different ways of living, and add to the kaleidoscope of colors that compose the country's demographic. In 
addition, even though it does not appear to be a consideration in training, the interns recognized students' academic and affective needs and linked these to learners' ethnic and cultural backgrounds.

This research suggests that teacher trainers might join their efforts to examine the ways the diversity in their nation can affect students' academic success. Pedagogy developed from a sociocultural framework will foster respectful interpersonal interactions and validate all learners' realities. The problems appear to be that top-down mandates have not allowed teachers to question their pedagogy and that not all future teachers understand ELT requirements at K12. It is clear that there is a need to address multilingual development and how to balance the use of students' languages in ELT. The one-year internship period seems an appropriate time to add the requirement of conducting action research in the training. This would provide the experience of the teacher as an actor and participant observer, and help prepare future teachers to become the nation's policy makers.

\section{Acknowledgements}

Our appreciation to Drs. Chris Liska Carger and Alexis E. Ball for their contribution to this project. Our thanks to the Ecuadorian teachers who participated in this study and to the administrators who facilitated these research efforts.

\section{References}

Allen, J. M., \& Nimon, K. (2007). Retrospective Pretest: A Practical Technique for Professional Development Evaluation. Journal of Industrial Teacher Education, 44(3), 27-42.

Bialystok, E. (2011). Reshaping the Mind: The Benefits of Bilingualism. Canadian Journal of Experimental Psychology, 65(4), 229-235.

Canagarajah, S. (2013). Translingual Practice: Global Englishes and Cosmopolitan Relations. Abingdon, UK: Routledge.

Burgin, X., \& Daniel, M. C. (2017). Language Teaching in an Ecuadorian Urban Secondary Institution [Una exploración de la enseñanza del inglés en una institución urbana en Ecuador. GIST Education and Learning Research Journal, 14, 107-134.

Cevallos-Estarellas, P. \& Bramwell, D. (2015). Ecuador, 2007-2014: Attempting a Radical Educational Transformation. In S. Schwartzman (ed.), Education in South America (pp. 329-361). London: Bloomsbury Academic.

Constitution of the Republic of Ecuador (2011). Registro Oficial 449. https://bit.ly/ $11 \mathrm{pv} 2 \mathrm{pA}$.

Corbin, J., \& Strauss, A. (2008). Basics of Qualitative Research: Teaching and Procedures for Developing Grounded Research $\left(3^{\text {rd }}\right.$ ed. $)$. Thousand Oaks, CA: SAGE Publications.

Daniel, M., \& Burgin, X. (2016). English Language Teaching in Ecuador: Teacher Preparation, Progress and Challenges of Professional Development. Paper presented at the TESOL International Convention and English Language Expo. Baltimore, 
Vol. 6, No. 1 Daniel \& Burgin: Investigating Future Educators Training to Teach ...

MD.

Daniel, M. (2016). Critical Pedagogy's Power in English Language Teaching. In L. R. Jacobs and C. Hastings (eds.), The Importance of Social Justice in English Language Teaching (pp. 25-38). Alexandria, VA: TESOL Press.

Daniel, M. C. (2010). La Preparación del Maestro: Una Examinación de las Voces de los Capacitadores que Enseñan en las Escuelas Normales de Guatemala [Teacher Preparation: An Examination of the Voices of Teacher Trainers Teaching in the Normal Schools of Guatemala]. Education and Learning Research Journal, GIST, 4(1), 127-137.

Ecuador Demographics Profile (2016, October). Retrieved from https://bit.ly/2H7Xp0m.

Ethnologue (2016). Languages of the world. Retrieved from https://bit.ly/2IVL2dE.

El Tiempo (2015, November 23). En el Ecuador se hablan 14 lenguas ancestrales [In Ecuador are spoken 14 ancestral languages]. Retrieved from https://bit.ly/2J0NS1a.

Faust, H. (2016). Understanding Privilege: Considerations for Teaching and Teacher Training toward Social Justice. In L. R. Jacob \& C. Hastings (eds.), The importance of social justice in English language teaching. (pp. 147-164). Alexandria, VA: TESOL Press.

Freire, P. (2002). Pedagogy of the Oppressed. New Your, NY: Continuum International.

Gallegos, R. R. (2008). Igualmente Pobres, Desigualmente ricos [Equally poor, unequally rich]. In R. R. Gallegos (ed.), Igualmente pobres, desigualmente ricos (pp. 150-220). Quito: Ariel-PNUD.

Garcia, O., \& Wei, L. (2014). Translanguaging: Language, Bilingualism, and Education. London, England: Palgrave MacMillan.

Goodman, Y., \& Allen, K. (2017). Language is a Resource: Revaluing Readers' Transliteracies through Miscue Analysis and Retrospective Miscue Analysis (RMA). In M.C. Daniel (ed.), Culture. Language and curricular choices, (pp. 5986). Lanham, MD: Rowman \& Littlefield.

González, N., Moll, L., \& Amanti, C. (eds.) (2005). Funds of Knowledge for Teaching in Latino Households. Mahwah, NJ: Lawrence Erlbaum Associates, Publishers.

Hall, C. (2016). A short introduction to social justice and ELT. In L. R. Jacob \& C. Hastings (eds.), The Importance of Social Justice in English Language Teaching (pp. 3-10). Alexandria, VA: TESOL Press.

Hawkins, M., \& Norton, B. (2009). Critical Language Teacher Education. In A. Burns \& J. Richards (Eds.). Cambridge guide to second language teacher education, (pp. 30-39). Cambridge, England: Cambridge University Press.

Instituto Nacional de Estadísticas y Censos (INEC) (2015). Retrieved from https://bit. ly/1y5pcrD.

Kincheloe, J. L. (2008). Critical Pedagogy Primer. New Yourk, NY: Peter Lang.

Malik, Z., Esaki-Smith, A., Lee, T., \& Ngan, B. (2015). English in Ecuador: An Examination of Policy, Perceptions, and Influencing Factors. England: British Council.

Government of Ecuador (2008). Resultados Pruebas Censales [Results Census Data]. Retrieved from https://bit.ly/2LKpgHu.

Ruiz, R. (1984). Orientations in language planning. NABE: The Journal for the National Association for Bilingual Education, 8(2), pp. 15-34.

Van Damme, W., Aguerrondo, I., Burgos, C. C., \& Campos, M. R. (2013). A Story of Change: How Ecuador Seeks to Sustain its Development Agenda through Large Scale Educational Reform. Paper Presented at UKFIET International Conference on Education and Development - Education and Development post 2015: Reflecting, Reviewing, Re-visioning. Oxford, England. 
Vygotsky, L. S. (1986). Thought and Language. Cambridge, MA: MIT Press.

Wertsch, J. M. (1990). The Voice of Rationality in a Sociocultural Approach to Mind. In L. C. Moll (ed.), Vygotsky and Education: Instructional Implications and Applications of Sociohistorical Psychology (pp. 111-126). Cambridge, UK: Cambridge University Press. 
